\title{
Multicenter Retrospective Study of Weekly Cetuximab Plus Paclitaxel for Recurrent or Metastatic Oral Squamous Cell Carcinoma
}

\author{
TOMOFUMI NARUSE ${ }^{1}$, SOUICHI YANAMOTO ${ }^{1}$, MITSUNOBU OTSURU $^{1}$, NOBUHIRO YAMAKAWA ${ }^{2}$, \\ TADAAKI KIRITA $^{2}$, YUKARI SHINTANI ${ }^{3}$, TATSUSHI MATSUMURA ${ }^{3}$, MASAYA OKURA $^{4,5}$, MASASHI SASAKI ${ }^{6}$, \\ YOSHIHIDE OTA ${ }^{6}$, SHIN-ICHI YAMADA ${ }^{7}$, HIROSHI KURITA ${ }^{7}$ and MASAHIRO UMEDA ${ }^{1}$; \\ JAPAN ORAL ONCOLOGY GROUP (JOOG) \\ ${ }^{1}$ Department of Clinical Oral Oncology, Graduate School of Biomedical Sciences, \\ Nagasaki University, Nagasaki, Japan; \\ ${ }^{2}$ Department of Oral and Maxillofacial Surgery, Nara Medical University, Kashihara, Japan; \\ ${ }^{3}$ Department of Oral and Maxillofacial Surgery, Wakayama Medical University, Wakayama, Japan; \\ ${ }^{4}$ First Department of Oral and Maxillofacial Surgery, \\ Graduate School of Dentistry, Osaka University, Osaka, Japan; \\ ${ }^{5}$ Oral and Maxillofacial Surgery, Saiseikai Matsusaka General Hospital, Matsusaka, Japan; \\ ${ }^{6}$ Department of Oral and Maxillofacial Surgery, Tokai University School of Medicine, Isehara, Japan; \\ ${ }^{7}$ Department of Dentistry and Oral Surgery, Shinshu University School of Medicine, Matsumoto, Japan
}

\begin{abstract}
Background/Aim: This study was conducted to compare the efficacy and safety of the weekly cetuximab plus paclitaxel (wCmab-PTX) regimen with those of the EXTREME regimen in patients with recurrent or metastatic oral squamous cell carcinoma (R/M OSCC). Patients and Methods: This multicenter retrospective study involved a chart review of the clinical records of R/M OSCC patients treated with wCmabPTX in each institution between January 2013 and December 2017. Data were collected, and the efficacy, safety, and treatment outcomes were analyzed. Results: The best overall response and disease control rates were $48.4 \%$ and $61.3 \%$, respectively. The median PFS and OS were 6 and 13 months, respectively. There was no significant difference in prognosis with or without previous platinum administration. The grade 3-4 adverse events were leukopenia (16.1\%), followed by acnelike rash (12.9\%), and neutropenia (9.7\%). All adverse events, excluding more than grade 3 infusion reactions, were tolerable and manageable. Conclusion: wCmab-PTX may be considered
\end{abstract}

This article is freely accessible online.

Correspondence to: Dr. Tomofumi Naruse, Department of Clinical Oral Oncology, Nagasaki University Graduate School of Biomedical Sciences, 1-7-1, Sakamoto, Nagasaki, 852-8588, Japan. Tel: +81 958497698, Fax: +81 958497700, e-mail: naruse12@nagasaki-u.ac.jp

Key Words: Cetuximab, paclitaxel, oral squamous cell carcinoma. as a treatment option for $R / M$ patients with OSCC that is refractory to platinum-based chemotherapy, or progressive disease after receiving chemotherapy.

Recurrent or metastatic $(\mathrm{R} / \mathrm{M})$ head and neck squamous cell carcinoma (HNSCC) has been associated consistently with a poor prognosis (1). In cases where salvage surgery is not indicated, systemic therapy may be the only treatment option to improve survival. In 2008, the EXTREME regimen, consisting of cetuximab, cisplatin, and 5-fluorouracil (5-FU), showed a significant improvement in overall survival (OS) among recurrent or metastatic (R/M) HNSCC patients (2). Currently, the National Comprehensive Cancer Network (NCCN) Clinical Practice Guidelines have suggested that systemic therapy, including the EXTREME regimen or immune checkpoint inhibitors (ICIs): pembrolizumab with or without the platinum regimen, is recommended as a category 1 therapy for its effectiveness in very advanced HNSCC (3). However, the EXTREME regimen cannot be used in all HNSCC patients because of the individual patient's history, including adverse events such as prior high-dose cisplatin and platinum-refractory disease. Moreover, this regimen necessitates hospital admission because of the 5-FU continuous infusion and the need for pre/post-chemotherapy hydration daily for 5 days. In pembrolizumab regimen, although a statistically significant improvement in OS has been suggested (4), many immunerelated adverse events have been reported and the evidence of efficacy or safety were insufficient in R/M OSCC. 
Conversely, the combination of weekly cetuximab plus paclitaxel (wCmab-PTX ) in a phase 2 study was well tolerated by R/M HNSCC patients who had a poor prognosis and may be a good treatment option for unfit patients when administered with platinum-based chemotherapy, although it is based on weak evidence (5). The advantage of this regimen is that it can be administered once per week in the outpatient setting. Recently, a comparison of the wCmabPTX regimen and the EXTREME regimen in the treatment of R/M HNSCC showed that the wCmab-PTX regimen significantly improved progression-free survival (PFS) (6). However, the evidence from this study in $\mathrm{R} / \mathrm{M}$ oral squamous cell carcinoma (OSCC) is considered to have low specificity because OSCC was not separately analyzed among all HNSCC. This multicenter retrospective study was conducted aiming at examining the efficacy and safety of the wCmab-PTX regimen in Japanese patients with R/M OSCC.

\section{Patients and Methods}

Patients and treatment. This multicenter retrospective study by the Japan Oral Oncology Group (JOOG) was undertaken through a review of the clinical records of R/M OSCC patients who received wCmab-PTX between January 2013 and December 2017. This study was approved by the independent ethics committees of the Clinical Research Review Boards of each institution (approval no.17022745). The wCmab-PTX regimen consisted of cetuximab $\left(400 \mathrm{mg} / \mathrm{m}^{2}\right.$, at induction, followed by $\left.250 \mathrm{mg} / \mathrm{m}^{2}\right)$ and paclitaxel $\left(80-100 \mathrm{mg} / \mathrm{m}^{2}\right)$; the treatment could be continued until disease progression or the occurrence of unacceptable adverse events.

The inclusion criteria were: histologically confirmed R/M OSCC; age 20 years or older; Eastern Cooperative Oncology Group (ECOG) performance status score 0-2 (7); and receiving wCmabPTX for R/M OSCC as the targeted disease. The exclusion criteria were: non-OSC-related complications that affected the prognosis, administration of cetuximab therapy before December 2012, or patients who were considered to be inappropriate candidates for this study.

Endpoints. The primary endpoints were the best overall response rate (ORR) and disease control rate (DCR). Overall responses included complete response (CR) and partial response (PR) that persisted for at least 4 weeks. Disease control included CR, PR, and stable disease (SD). These responses were defined according to the Response Evaluation Criteria in Solid Tumors (8). The secondary endpoints were progression-free survival (PFS) and OS. Subgroup analyses were performed to determine the difference in survival rates of first-line or later-line treatment, locoregional recurrence or distant metastasis, absence or presence of previous platinum chemotherapy, and absence or presence of acne-like rash. PFS was defined as the time from the date of the first cetuximab administration to the date of progressive disease (PD) or relapse, whichever occurred first. OS was defined as the time from the date of cetuximab administration to the date of death. Adverse events (AEs) were evaluated according to the National Cancer Institute Common Terminology Criteria for Adverse Events version 4.0 (9).
Table I. Patients characteristics.

\begin{tabular}{lc}
\hline Number of patients & 31 \\
Age, years, median (range) & $64(26-81)$ \\
Male, $\mathrm{n}(\%)$ & $24(77.4)$ \\
Primary site, $\mathrm{n}(\%)$ & $10(32.2)$ \\
Tongue & $14(45.2)$ \\
Gingiva & $4(12.9)$ \\
Oral floor & $2(6.5)$ \\
Primary intraosseous & $1(3.2)$ \\
Buccal & $23 / 7 / 1(74.2 / 22.6 / 3.2)$ \\
ECOG PS 0/1/2, $\mathrm{n}(\%)$ & $16(51.6)$ \\
Type of recurrence, $\mathrm{n}(\%)$ & $15(48.4)$ \\
Locoregional & \\
Distant metastasis & $5(16.1)$ \\
Previous platinum chemotherapy, $\mathrm{n}(\%)$ & $26(83.9)$ \\
Absent & \\
Present & $16(51.6)$ \\
Chemotherapy line, $\mathrm{n}(\%)$ & $15(48.4)$ \\
First line & \\
Later line & $1-70$ \\
Number of treatment cycles, $\mathrm{n}(\%)$ & 19 \\
Range & \\
Median &
\end{tabular}

PS: Performance status; ECOG: Eastern Cooperative Oncology Group.

Table II. Efficacy of wCmab-PTX.

\begin{tabular}{lc}
\hline Number of patients & 31 \\
Best response, $\mathrm{n}(\%)$ & \\
$\mathrm{CR} / \mathrm{PR} / \mathrm{SD} / \mathrm{PD} / \mathrm{NE}$ & $4 / 11 / 6 / 8 / 2$ \\
Overall response, $\mathrm{n}(\%)$ & $13 / 35.4 / 19.3 / 25.8 / 6.5)$ \\
Disease control, $\mathrm{n}(\%)$ & $21(61.3)$ \\
Overall response (First line), n (\%) & $8(50.0)$ \\
Overall response (later line), n (\%) & $7(46.7)$ \\
\hline
\end{tabular}

CR: Complete response; PR: partial response; SD: stable disease; PD: progressive disease; wCmab-PTX: weekly cetuximab plus paclitaxel.

Statistical analysis. All statistical analyses were performed using SPSS version 24.0 (Japan IBM Co., Tokyo, Japan). PFS and OS curves were calculated using the Kaplan-Meier method and compared using the $\log$-rank test. Statistical significance was set at $p<0.05$.

\section{Results}

Patient characteristics. The clinicopathological characteristics of the participants are summarized in Table I. This study enrolled 31 patients who were treated during the 5-year study period; $77.4 \%$ of the patients were male and $22.6 \%$ were female, and 30 patients had an ECOG performance status of 0 or 1 . The median age of the patients was 64 years (range=26-81 years). The most common site of the primary tumor was the gingiva $(45.2 \%)$, followed by the tongue $(32.2 \%)$, oral floor $(12.9 \%)$, primary intraosseous $(6.5 \%)$, and 

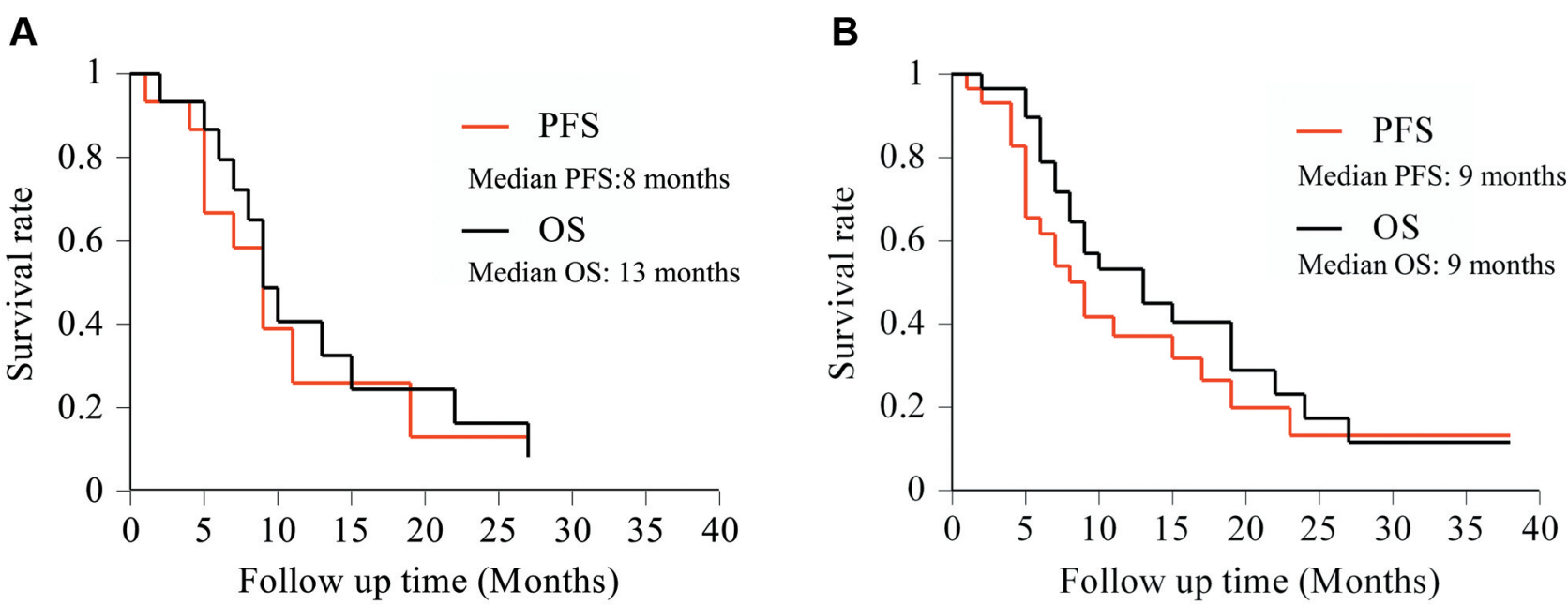

Figure 1. Kaplan-Meier survival curves. (A) Progression-free survival (PFS) and (B) overall survival (OS) (First line only).

buccal mucosa $(3.2 \%)$. The targeted disease was locoregional recurrence in only $51.6 \%$ of patients and distant metastasis in $48.4 \%$; 24 patients had received platinum-based chemotherapy as a previous treatment.

Efficacy. The best ORR was $48.4 \%$, with a CR rate of $28.6 \%$ and a PR rate of $23.8 \%$. The DCR was $61.3 \%$, which included 6 patients with SD. The subgroup analysis compared the treatment efficacy of wCmab-PTX as first-line or later-line treatment. The best ORR in patients with wCmab-PTX as first-line treatment was $50.0 \%$, whereas the best ORR with later-line treatment was $46.7 \%$ (Table II).

Treatment outcome. The median PFS and OS in all patients were 8 and 13 months, respectively. The median PFS and OS in patients who underwent wCmab-PTX as first-line treatment were 9 and 9 months, respectively (Figure 1A and B). In the subgroup analysis stratified by the target disease (locoregional recurrence $v s$. distant metastasis), previous chemotherapy (platinum absent $v s$. platinum present), and adverse events (acne-like rash $<\mathrm{G} 2 v s . \geq \mathrm{G} 2$ ), the median PFS and OS in patients with distant metastasis were 6 and 12 months, respectively, whereas those in patients with only locoregional recurrence were 8 and 10 months, respectively; there was a significant difference in the PFS ( $p=0.016$; Figure 2A and B). The median PFS and OS in patients without and with platinum therapy were 7.25 and 10 months and 7.5 and 11 months, respectively, which indicated no significant difference (Figure $2 \mathrm{C}$ and D). The median PFS in patients with an acne-like rash G0-1 was 8 months, whereas the median PFS in patients with G2-4 was 9 months, which indicated no significant intergroup difference. The median OS of patients with acne-like rash G01 was 8 months, whereas the median OS of patients with G2-
4 was 19 months, which indicated a significant intergroup difference ( $p=0.022$; Figure $2 \mathrm{E}$ and $\mathrm{F})$.

Safety. Treatment-related grade 3-4 AEs were reported in 12 patients (Table III). There were two grade 3 infusion reactions among patients receiving cetuximab, which resulted in withdrawal from therapy. The commonest grade 3 or 4 AEs were leukopenia $(16.1 \%)$, followed by an acnelike rash $(12.9 \%)$ and neutropenia $(9.7 \%)$. Grade 2 peripheral neuropathies were observed in two patients and necessitated dose reduction or temporary cessation of paclitaxel therapy. No cases of interstitial pneumonia were observed.

\section{Discussion}

In 2008, the EXTREME trial found that the addition of cetuximab to the standard regimen of platinum and 5-FU improved the median OS and PFS (2). Since then, several studies have been performed, and cetuximab plus platinum and 5-FU therapy have been recognized as the first-line therapy for patients with R/M HNSCC as recommended in international treatment guidelines $(3,10)$. However, this regimen is difficult to use in patients undergoing platinumbased chemotherapy. In a phase 2 study, wCmab-PTX was well tolerated by patients with a poor prognosis in $\mathrm{R} / \mathrm{M}$ HNSCC (5). In addition, the results of many prospective and retrospective studies have suggested favorable treatment outcomes for R/M HNSCC. However, that study was based on trials among HNSCC patients (approximately 15\%-45\% in $\mathrm{R} / \mathrm{M}$ OSCC), and there is insufficient evidence of treatment outcomes specific to OSCC. Therefore, we focused on the efficacy and safety of wCmab-PTX in Japanese patients with R/M OSCC. 

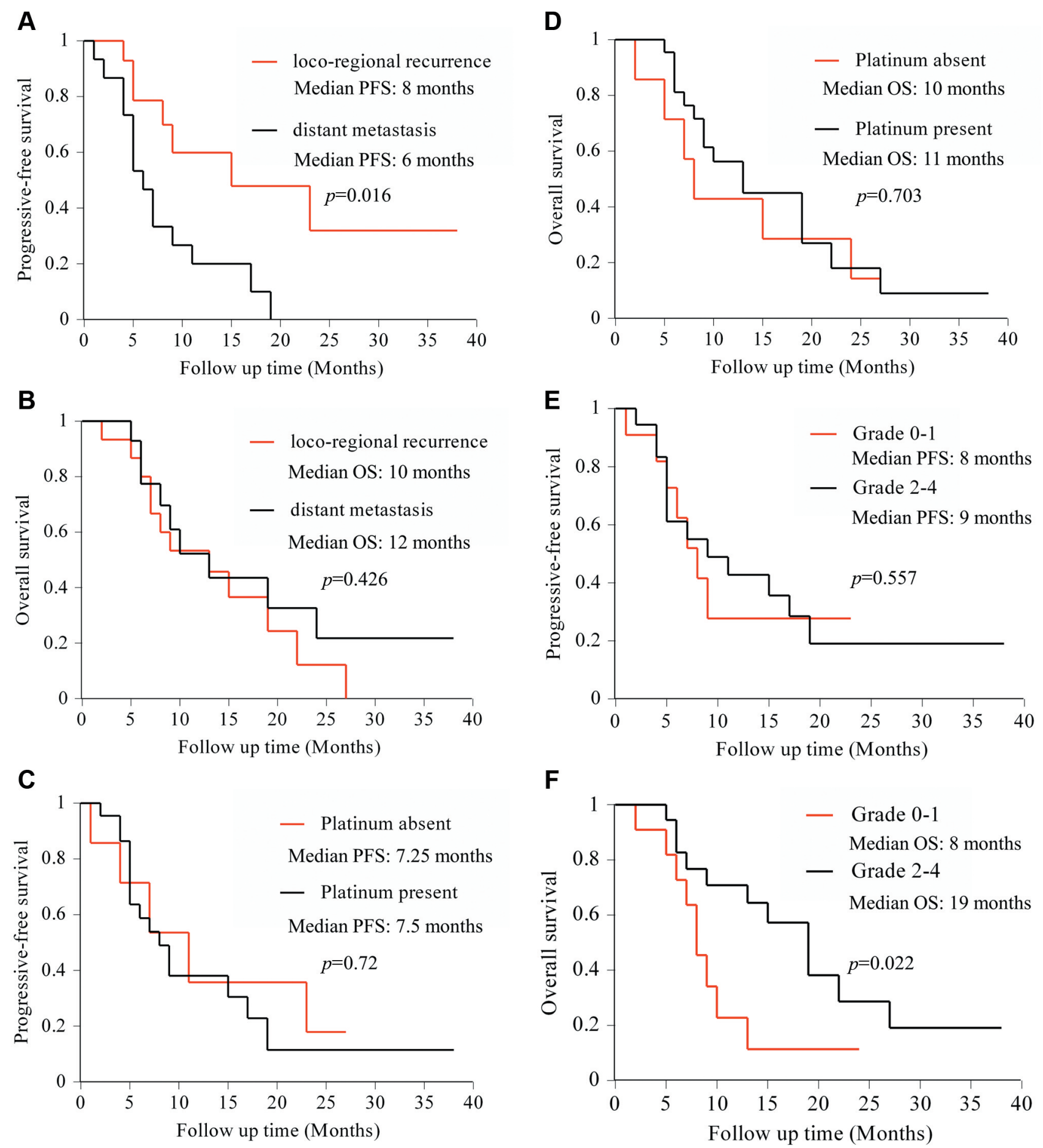

Figure 2. Kaplan-Meier survival curves in subgroup analysis. (A) Progression-free survival (PFS) for locoregional recurrence and distant metastasis; (B) OS for locoregional recurrence and distant metastasis; (C) PFS for previous platinum chemotherapy absent and present; (D) OS for previous platinum chemotherapy absent and present; (E) PFS for acne like rash $<G 2$ and $\geq G 2$; and (f) OS for acne like rash $<G 2$ and $\geq G 2$.

To the best of our knowledge, our study comprised a larger cohort (31 cases) of patients with R/M OSCC than previous studies that have investigated this aspect to date.
Although wCmab-PTX studies of patients with R/M HNSCC, including one with the largest cohort, have been reported, subgroup analyses were not performed specifically 
Table III. Adverse events.

\begin{tabular}{lc}
\hline Adverse events, $\mathrm{n}(\%)$ & Grade $>3$ \\
\hline Any events & $12(38.7)$ \\
Infusion reaction & $2(6.5)$ \\
Acne like rash & $4(12.9)$ \\
Leucopenia & $5(16.1)$ \\
Neutropenia & $3(9.7)$ \\
Anemia & $1(3.2)$ \\
Hepatic dysfunction & $1(3.2)$ \\
Nausea & $1(3.2)$ \\
Fatigue & $1(3.2)$ \\
Decreased $\mathrm{Mg}$ & $1(3.2)$ \\
\hline
\end{tabular}

for an R/M OSCC sub-cohort (11-14). Enokida et al. (15) reported that $\mathrm{wCmab}-\mathrm{PTX}$ as first-line therapy for $\mathrm{R} / \mathrm{M}$ OSCC obtained the ORR in $60 \%$ of their participants $(6 / 10$ patients); however, their subgroup analysis of PFS and OS did not compare outcomes between patients with $\mathrm{R} / \mathrm{M}$ OSCC and patients with other HNSCCs. Ferreira et al. (16) reported that there were no significant differences in PFS and OS when comparing the primary sites in HNSCCs. Nakano et al. (5) performed a subgroup analysis of patients treated with the wCmab-PTX regimen and the EXTREME regimen as a first-line therapy for HNSCC and showed that the wCmab-PTX regimen for R/M OSCC is more effective in prolonging PFS than the EXTREME regimen; however, their study included a small number of patients with $\mathrm{R} / \mathrm{M}$ OSCC. Conversely, Yanamoto et al. (17) reported that the EXTREME regimen is suitable for the treatment of $\mathrm{R} / \mathrm{M}$ OSCC (ORR: 46.2\%, median PFS and OS: 5.6 and 12.1 months, respectively). To the best of our knowledge, our study comprised the largest cohort of patients with $\mathrm{R} / \mathrm{M}$ OSCC who were treated with the EXTREME regimen. Comparing the results of our study with those of previous reports, the treatment outcomes of wCmab-PTX were comparable.

The prognosis of OSCC with distant metastasis is extremely poor, and some investigators reported that the median or average survival time after a diagnosis of distant metastasis was less than 6 months $(18,19)$, with a 1-year OS of $20 \%$ before cetuximab was approved as a therapy (20). Furthermore, as distant metastasis reduces the quality of life, improved treatment of distant metastasis is an important consideration. In distant metastasis in OSCC, treatment with the EXTREME regimen achieved a median PFS of 7.8 months and a median OS of 12.0 months (17). In our study, wCmab-PTX may have contributed to prolongation of OS despite insufficient disease control in distant metastasis. Some investigators have reported that the presence or absence of previous platinum chemotherapy did not significantly affect treatment outcomes (12-15). Therefore,
wCmab-PTX could be effective in prolonging OS with less burden on the patient regardless of the content of previous chemotherapy. In addition, the median OS in patients with acne-like rash G2-4 was significantly longer than that in patients with acne-like rash G0-1 in our study. Similar results have been reported in the Bonner trial (21). Taken together, our results suggest that wCmab-PTX could be a useful treatment option for patients with $\mathrm{R} / \mathrm{M}$ OSCC that is refractory to platinum-based chemotherapy, have PD after receiving ICIs, or who are unsuitable for ICIs.

The incidence of grade 3/4 adverse events in our study was $38.7 \%$, including leukopenia events (16.1\%), skin rash $(12.9 \%)$, and infusion reaction $(6.5 \%)$. The results of our study are consistent with those of previous studies in Japanese cohorts $(6,14,15)$. Moreover, infusion reactions occurred more frequently in our study than in previous studies $(5,6,14$, $15)$. Two cases in which the infusion reaction occurred were in the same institution. This may be because, despite no actual evidence of a correlation, increased rates of cetuximab infusion reaction have been reported in areas of high tick prevalence (22). We have reported that our institution is a site where infusion reactions are frequently reported (20). The difference between the frequency of infusion reactions and specific regions was considered controversial. However, all adverse events, excluding more G3 infusion reactions, were tolerable and manageable.

A potential weakness of our study is its retrospective study design and the small number of cases. Moreover, we did not compare the efficacy of wCmab-PTX with that of other regimens. Therefore, our findings may contain many biases and should be interpreted with caution.

In conclusion, the findings of our study suggest that wCmab-PTX as a first-line or later-line therapy is a good treatment option for the systemic therapy of R/M OSCC. More recently, Cmab-PTX was significantly associated with a higher ORR than the other chemotherapies that were used as salvage chemotherapy after PD on ICIs (23). Clinical studies to evaluate the efficacy of wCmab-PTX as salvage chemotherapy after ICIs are important to determine effective therapeutic options in R/M OSCC.

\section{Conflicts of Interest}

The Authors declare that they have no conflicts of interest in relation to this study.

\section{Authors' Contributions}

All Authors contributed to the conception and design of the study. NY, YS, MO, MS and SY contributed to the collection and interpretation of the data. Data analysis was performed by TN, SY and MO. The first draft of the manuscript was written by TN, and all the Authors commented on the previous versions of the manuscript. All Authors read and approved the final manuscript. 


\section{Acknowledgements}

The Authors would like to thank Editage (http://www.editage.jp) for English language editing.

\section{References}

1 Lala M, Chirovsky D, Cheng JD and Mayawala K: Clinical outcomes with therapies for previously treated recurrent/metastatic head-and-neck squamous cell carcinoma (R/M HNSCC): A systematic literature review. Oral Oncol 84: 108-120, 2018. PMID: 30115469. DOI: 10.1016/j.oraloncology.2018.07.005

2 Vermorken JB, Mesia R, Rivera F, Remenar E, Kawecki A, Rottey S, Erfan J, Zabolotnyy D, Kienzer HR, Cupissol D, Peyrade F, Benasso M, Vynnychenko I, De Raucourt D, Bokemeyer C, Schueler A, Amellal N and Hitt R: Platinumbased chemotherapy plus cetuximab in head and neck cancer. $\mathrm{N}$ Engl J Med 359(11): 1116-1127, 2008. PMID: 18784101. DOI: 10.1056/NEJMoa0802656

3 National Comprehensive Cancer Network. Clinical practice guidelines in oncology head and neck cancers, Version 2. National Comprehensive Cancer Network; 2021. Available at: https://www.nccn.org/professionals/physician_gls/pdf/head-andneck.pdf [Last accessed on March 31, 2021]

4 Burtness B, Harrington KJ, Greil R, Soulières D, Tahara M, de Castro G Jr, Psyrri A, Basté N, Neupane P, Bratland Å, Fuereder T, Hughes BGM, Mesía R, Ngamphaiboon N, Rordorf T, Wan Ishak WZ, Hong RL, González Mendoza R, Roy A, Zhang Y, Gumuscu B, Cheng JD, Jin F, Rischin D and KEYNOTE-048 Investigators: Pembrolizumab alone or with chemotherapy versus cetuximab with chemotherapy for recurrent or metastatic squamous cell carcinoma of the head and neck (KEYNOTE048): a randomised, open-label, phase 3 study. Lancet 394(10212): 1915-1928, 2019. PMID: 31679945. DOI: 10.1016/S0140-6736(19)32591-7

5 Hitt R, Irigoyen A, Cortes-Funes H, Grau JJ, García-Sáenz JA, Cruz-Hernandez JJ and Spanish Head and Neck Cancer Cooperative Group (TTCC): Phase II study of the combination of cetuximab and weekly paclitaxel in the first-line treatment of patients with recurrent and/or metastatic squamous cell carcinoma of head and neck. Ann Oncol 23(4): 1016-1022, 2012. PMID: 21865152. DOI: $10.1093 /$ annonc/mdr367

6 Nakano K, Marshall S, Taira S, Sato Y, Tomomatsu J, Sasaki T, Shimbashi W, Fukushima H, Yonekawa H, Mitani H, Kawabata $\mathrm{K}$ and Takahashi S: A comparison of weekly paclitaxel and cetuximab with the EXTREME regimen in the treatment of recurrent/metastatic squamous cell head and neck carcinoma. Oral Oncol 73: 21-26, 2017. PMID: 28939072. DOI: 10.1016/j.oraloncology.2017.07.022

7 Sok M, Zavrl M, Greif B and Srpčič M: Objective assessment of WHO/ECOG performance status. Support Care Cancer 27(10): 3793-3798, 2019. PMID: 30721369. DOI: 10.1007/ s00520-018-4597-z

8 Eisenhauer EA, Therasse P, Bogaerts J, Schwartz LH, Sargent D, Ford R, Dancey J, Arbuck S, Gwyther S, Mooney M, Rubinstein L, Shankar L, Dodd L, Kaplan R, Lacombe D and Verweij J: New response evaluation criteria in solid tumours: revised RECIST guideline (version 1.1). Eur J Cancer 45(2): 228-247, 2009. PMID: 19097774. DOI: $10.1016 /$ j.ejca.2008.10.026
9 Chen AP, Setser A, Anadkat MJ, Cotliar J, Olsen EA, Garden BC and Lacouture ME: Grading dermatologic adverse events of cancer treatments: the Common Terminology Criteria for Adverse Events Version 4.0. J Am Acad Dermatol 67(5): 10251039, 2012. PMID: 22502948. DOI: 10.1016/j.jaad.2012.02.010

10 Grégoire V, Lefebvre JL, Licitra L, Felip E and EHNS-ESMOESTRO Guidelines Working Group: Squamous cell carcinoma of the head and neck: EHNS-ESMO-ESTRO Clinical Practice Guidelines for diagnosis, treatment and follow-up. Ann Oncol 21(Suppl 5): v184-v186, 2010. PMID: 20555077. DOI: 10.1093/ annonc/mdq 185

11 Yoshino T, Hasegawa Y, Takahashi S, Monden N, Homma A, Okami K, Onozawa Y, Fujii M, Taguchi T, de Blas B, Beier F and Tahara M: Platinum-based chemotherapy plus cetuximab for the first-line treatment of Japanese patients with recurrent and/or metastatic squamous cell carcinoma of the head and neck: results of a phase II trial. Jpn J Clin Oncol 43(5): 524-531, 2013. PMID: 23479384. DOI: 10.1093/jjco/hyt034

12 Jiménez B, Trigo JM, Pajares BI, Sáez MI, Quero C, Navarro V, Llácer C, Medina L, Rueda A and Alba E: Efficacy and safety of weekly paclitaxel combined with cetuximab in the treatment of pretreated recurrent/metastatic head and neck cancer patients. Oral Oncol 49(2): 182-185, 2013. PMID: 23026069. DOI: 10.1016/j.oraloncology.2012.09.003

13 Bernad IP, Trufero JM, Urquizu LC, Pazo Cid RA, de Miguel AC, Agustin MJ, Lanzuela M and Antón A: Activity of weekly paclitaxel-cetuximab chemotherapy in unselected patients with recurrent/metastatic head and neck squamous cell carcinoma: prognostic factors. Clin Transl Oncol 19(6): 769-776, 2017. PMID: 28120324. DOI: 10.1007/s12094-016-1604-z

14 Fushimi C, Baba D, Masubuchi T, Yamazaki M, Kitani Y, Kitajima T, Tanaka J, Hanyu K, Tanaka N, Miura K and Tada Y: Weekly cetuximab and paclitaxel for recurrent or metastatic head and neck squamous cell carcinoma. In Vivo 34(5): 2653-2657, 2020. PMID: 32871796. DOI: 10.21873/invivo.12084

15 Enokida T, Okano S, Fujisawa T, Ueda Y, Uozumi S and Tahara M: Paclitaxel plus cetuximab as 1 st line chemotherapy in platinum-based chemoradiotherapy-refractory patients with squamous cell carcinoma of the head and neck. Front Oncol 8: 339, 2018. PMID: 30211118. DOI: 10.3389/fonc.2018.00339

16 Pellini Ferreira B, Redman M, Baker KK, Martins R, Eaton KD, Chow LQM, Baik CS, Goulart B, Lee SM, Santana-Davila R and Rodriguez CP: Predictors of outcome with cetuximab and paclitaxel for head and neck squamous cell carcinoma. Laryngoscope 127(7): 1583-1588, 2017. PMID: 27905113. DOI: 10.1002/lary.26422

17 Yanamoto S, Umeda M, Kioi M, Kirita T, Yamashita T, Hiratsuka H, Yokoo S, Tanzawa H, Uzawa N, Shibahara T, Ota Y, Kurita H, Okura M, Hamakawa H, Kusukawa J and Tohnai I: Multicenter retrospective study of cetuximab plus platinumbased chemotherapy for recurrent or metastatic oral squamous cell carcinoma. Cancer Chemother Pharmacol 81(3): 549-554, 2018. PMID: 29383483. DOI: 10.1007/s00280-018-3531-x

18 Sakamoto Y, Matsushita Y, Yamada S, Yanamoto S, Shiraishi T, Asahina I and Umeda M: Risk factors of distant metastasis in patients with squamous cell carcinoma of the oral cavity. Oral Surg Oral Med Oral Pathol Oral Radiol 121(5): 474-480, 2016. PMID: 27068308. DOI: 10.1016/j.oooo.2015.11.022

19 Sumioka S, Sawai NY, Kishino M, Ishihama K, Minami M and Okura M: Risk factors for distant metastasis in squamous cell 
carcinoma of the oral cavity. J Oral Maxillofac Surg 71(7): 1291-1297, 2013. PMID: 23434157. DOI: 10.1016/j.joms.2012. 12.023

20 Naruse T, Yanamoto S, Matsushita Y, Sakamoto Y, Morishita K, Ohba S, Shiraishi T, Yamada SI, Asahina I and Umeda M: Cetuximab for the treatment of locally advanced and recurrent/metastatic oral cancer: An investigation of distant metastasis. Mol Clin Oncol 5(2): 246-252, 2016. PMID: 27446558. DOI: $10.3892 / \mathrm{mco} .2016 .928$

21 Bonner JA, Harari PM, Giralt J, Azarnia N, Shin DM, Cohen RB, Jones CU, Sur R, Raben D, Jassem J, Ove R, Kies MS, Baselga J, Youssoufian H, Amellal N, Rowinsky EK and Ang KK: Radiotherapy plus cetuximab for squamous-cell carcinoma of the head and neck. N Engl J Med 354(6): 567-578, 2006. PMID: 16467544. DOI: 10.1056/NEJMoa053422

22 Yuile A, Fanuli C, van Nunen S, Diakos C, Clarke S, Steiner C, MacMillan R, Oatley $\mathrm{M}$ and Pavlakis $\mathrm{N}$ : Increased rates of cetuximab reactions in tick prevalent regions and a proposed protocol for risk mitigation. Asia Pac J Clin Oncol, 2020. PMID: 32970939. DOI: 10.1111/ajco.13465
23 Saleh K, Daste A, Martin N, Pons-Tostivint E, Auperin A, Herrera-Gomez RG, Baste-Rotllan N, Bidault F, Guigay J, Le Tourneau C, Saada-Bouzid E and Even C: Response to salvage chemotherapy after progression on immune checkpoint inhibitors in patients with recurrent and/or metastatic squamous cell carcinoma of the head and neck. Eur J Cancer 121: 123-129, 2019. PMID: 31574417. DOI: 10.1016/j.ejca.2019.08.026
Received September 5, 2021

Revised September 28, 2021

Accepted September 29, 2021 